\title{
Genotoxicidade do composto Azadiractina avaliado através do Ensaio Cometa utilizando Danio rerio (Hamilton 1822) como organismo teste
}

\author{
Alana Nunes Rael ${ }^{1}$
}

Alexandre Rieger ${ }^{2}$

\section{RESUMO}

A azadiractina consiste no óleo obtido a partir de sementes secas de Azadirachta indica A. Juss. (Família: Meliaceae). É comercializado como um biopesticida para controle de pragas na agricultura orgânica por ser um agente "eco-amigável". Sua ação ocorre impedindo o desenvolvimento das larvas sendo aplicado por pulverização sobre as folhas (1,2g/100 L). Resíduos dos pesticidas, incluindo os biopesticidas, podem causar efeitos deletérios a organismos que não são o seu alvo. Assim, o presente trabalho avaliou o efeito genotóxico resultante da exposição da azadiractina por sete dias em peixes Danio rerio - Hamilton 1822, utilizando o Ensaio Cometa (EC) e a mortalidade pela análise de sobrevivência. Foram expostos três grupos testes $(1,2 ; 0,3$ e $0,15 \mu \mathrm{g} / \mathrm{mL})$, um controle negativo (CN) e um controle positivo (CP) (CuSO4 0,1 mg/L). Os resultados do EC sugerem efeito de genotoxicidade nas três concentrações, pois tanto a Frequência de Dano (FD) como o Índice de Dano (ID) utilizando os eritrócitos do $D$. rerio estavam significativamente aumentados em relação ao CN. A mortalidade foi de $100 \%$ em até 13 dias após a exposição à azadiractina sugerindo uma elevada toxicidade. Portanto, a utilização do biopesticida azadiractina deve ser realizada com precaução para não aumentar a contaminação ambiental, especialmente nos ecossistemas aquáticos.

Palavras-chave: Danio rerio. Azadirachta indica. Azadiractina. Genotoxicidade. Neem. Ensaio Cometa.

\begin{abstract}
Azadirachtin consists of the oil obtained from dried seeds of Azadirachta indica A. Juss. (Family: Meliaceae). It is marketed as a biopesticide for pest control in organic farming as it is an "eco-friendly" agent. Its action occurs preventing the development of the larvae being applied by spraying on the leaves $(1.2 \mathrm{~g} / 100 \mathrm{~L})$. Residues of pesticides, including biopesticides, can cause deleterious effects to organisms that are not their target. Thus, the present work evaluated the genotoxic effect resulting from the exposure of azadirachtin for 7 days in Danio rerio - Hamilton 1822 fish, using Comet Assay (CA) and mortality by survival analysis. Three test groups $(1.2,0.3$ and $0.15 \mu \mathrm{g} / \mathrm{mL}$ ), one negative control (NC) and one positive control (PC) $(0.1 \mathrm{mg} / \mathrm{L} \mathrm{CuSO} 4)$ were exposed. The CA results suggest a genotoxicity effect at the 3 concentrations since both the Damage Frequency (DF) and the Damage Index (DI) using the $D$. rerio erythrocytes were significantly increased in relation to the CN. Mortality was $100 \%$ within 13 days after exposure to azadirachtin suggesting high toxicity. Therefore, the use of azadirachtin biopesticide should be carried out with caution so as not to increase environmental contamination, especially in aquatic ecosystems.
\end{abstract}

Keywords: Danio rerio. Azadirachta indica. Azadirachtin. Genotoxicity. Neem. Comet Assay.

\footnotetext{
${ }^{1}$ Acadêmica do Curso de Ciências Biológicas Bacharelado da Universidade de Santa Cruz do Sul.

${ }^{2}$ Professor do Departamento de Biologia e Farmácia da Universidade de Santa Cruz do Sul <rieger@unisc.br>
} 


\section{INTRODUÇÃO}

A sociedade atual tem uma demanda crescente em consumir produtos agrícolas denominados orgânicos, por serem livres de agrotóxicos. Para o manejo destes produtos é permitida somente a utilização de substâncias químicas de origem natural, conhecidas como biopesticidas, destacando-se, entre elas, alguns produtos derivados do óleo de Neem ou Nim, cujo princípio ativo é a azadiractina. No Brasil, há formulações comercias que estão aprovadas para uso, contudo existem também formulações caseiras produzidas e empregadas livremente entre diversos produtores orgânicos baseados na informação de que como se trata de produto de origem natural não apresenta riscos à saúde.

Os produtos que contém em sua formulação a azadiractina são classificados como medianamente tóxicos e pouco perigosos ao meio ambiente. A sua principal utilização é no controle do crescimento e desenvolvimento de larvas relacionadas a pragas de insetos na agricultura. O surgimento deste biopesticida como uma alternativa aos pesticidas químicos convencionais fez com que muitas pesquisas apontando a sua eficiência fossem desenvolvidas.

Assim, uma série de pesquisas estão sendo realizadas visando elucidar o mecanismo de ação da azadiractina para entender os seus efeitos sobre os sistemas biológicos, tanto em nível ecológico, como no organismo e nas suas células. A consequência desse maior conhecimento implicou em aumentar a sensibilidade dos testes que caracterizam a sua ação toxicológica em diferentes grupos de organismos e meios, uma vez este efeito pode persistir no meio diretamente ou através de seus catabólitos. Desta forma, ensaios ecotoxicológicos com novos organismos testes têm sido realizados, bem como ensaios de cito e genotoxicidade. Os resultados destes ensaios podem tanto servir para auxiliar a elucidar o mecanismo de ação da azadiractina, como também para investigar o seu potencial de contaminar o ambiente e afetar outros níveis de tróficos.

Assim, no presente trabalho foi avaliado o efeito genotóxico da azadiractina no meio aquoso frente a exemplares do peixe conhecido como Paulistinha ou Zebra-fish.

\section{FUNDAMENTAÇÃO TEÓRICA}

Azadirachta indica A. Juss (Meliaceae), conhecida como Neem é uma planta originária da Índia. As sementes de Neem são preparadas por prensagem mecânica para a 
obtenção do óleo que contém cerca de 100 componentes fitoquímicos que podem ser explorados para uso na saúde humana e no controle de pestes (Figura 1). Entre estes compostos destacam-se os triterpenóides, sendo que o mais abundante e importante deles é a azadiractina que possui atividade biopesticida (CAMPOS et al., 2016).

\section{Figura 1. Estruturas da árvore de Neem}
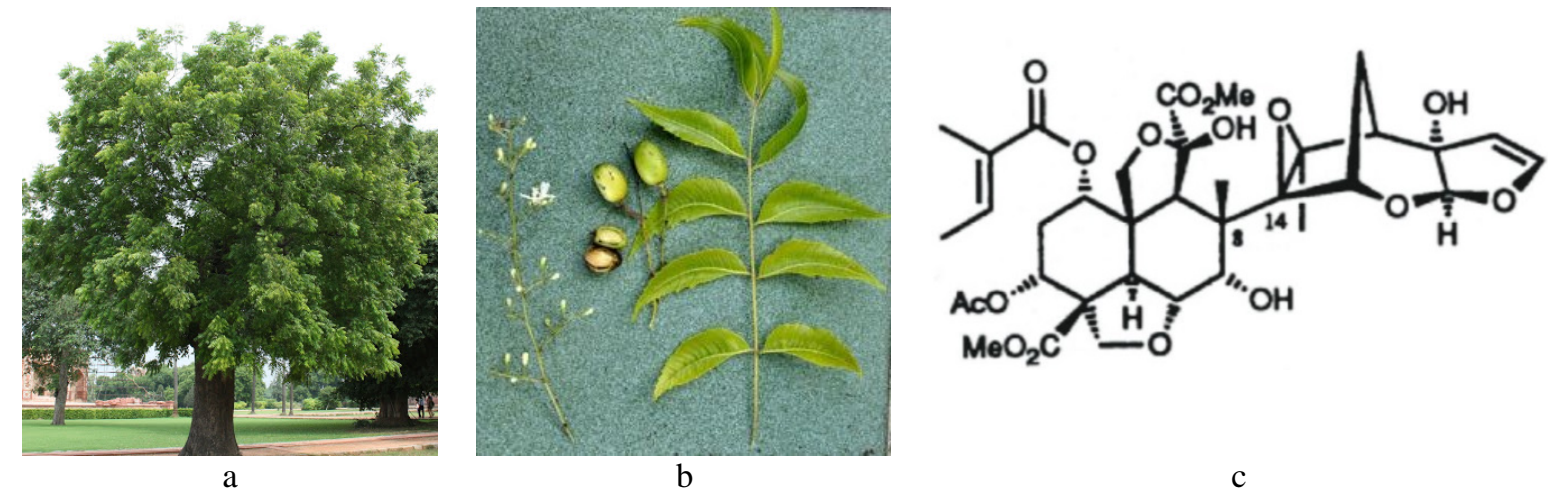

a: Árvore de Neem b: Folha, fruto/semente e floração da árvore de Neem c: Estrutura molecular da azadiractina. Fonte: Adaptado de VEITCH; BOYER; LEY, 2008.

A azadiractina tem sido usada para controle de uma série de pragas de insetos em diferentes culturas de plantas (MORDUE(LUNTZ); NISBET, 2000). Por exemplo, ela atua de modo eficiente como biopesticida no controle de hemípteras na cultura do morangueiro bem como em videiras (BOTTON et al., 2013). Também é utilizada no controle de lepidópteras (REDDY; ANTWI, 2016) e dípteros como moscas (PAVLOVA et al., 2017) e mosquitos, especialmente para combater o Aedes aegypti (BENELLI et al., 2017; CHANDRAMOHAN et al., 2016).

A ação de biocida da azadiractina tem sido demonstrada em diversas fases do desenvolvimento de insetos caracterizando o seu potencial de uso como ovicida, larvicida, pupicida e até mesmo como um agente que diminui a chance de ovoposição sobre um substrato vegetal. Dessa forma, devido aos seus múltiplos efeitos é improvável a aquisição de resistência pelos insetos a sua utilização (BENELLI et al., 2017).

É reconhecido que a azadiractina tem influência sobre os insetos de diferentes formas, tais como interferir na regulação dos sistemas de crescimento, alimentar e reprodutor. A eficácia primordial do uso dos inseticidas a base de azadiractina está nos seus efeitos tóxicos fisiológicos (MORDUE e NISBET, 2000). Esses efeitos se dão por ações disruptoras em relação ao desenvolvimento, bem como ações inibidoras sobre a alimentação (VEITCH; BOYER; LEY, 2008).

Segundo Agência Nacional de Vigilância Sanitária (ANVISA, 2016), a azadiractina está enquadrada na classe toxicológica II (altamente tóxica) devendo ser empregada como Revista Jovens Pesquisadores, Santa Cruz do Sul, v.7, n. 2, p. 46-62, jul./dez. 2017. 
uma aplicação foliar em diversos tipos de culturas relacionadas à jardinagem amadora. Contudo, quanto ao potencial de periculosidade ambiental é enquadrada na classe IV (produto pouco perigoso ao ambiente).

Em relação à contaminação ambiental pela azadiractina existem estudos controversos. Alguns autores sugerem alto risco de contaminação ambiental enquanto outros sugerem que efeitos sobre organismos invertebrados não alvos, incluindo insetos benéficos, é de baixo risco (HOLMES; MACQUARRIE, 2016). Entretanto, em um estudo com doses controladas de azadiractina em laboratório, os autores encontram uma mortalidade elevada dos parasitoides utilizados no controle biológico de lepidópteros, além da persistência da azadiractina no meio, sugerindo que ela deva ser usada só de forma complementar quando necessária (FIRAKE; THUBRU; BEHERE, 2017).

Efeitos de intoxicação aguda e subaguda do óleo de Neem em aves e mamíferos incluindo humanos foram recentemente alvo de revisão (RAJ, 2014). O autor descreve efeitos importantes de intoxicação em diferentes órgãos, especialmente fígado e rim, de animais que consumiram o óleo de Neem através da água contaminada, bem como por contato direto e termina concluindo que embora o seu uso seja promissor devido às propriedades químicas e até farmacológicas, ele deva ser realizado com cautela.

Os efeitos da azadiractina em ambientes aquáticos também tem sido alvo de diferentes estudos. A redução na população adulta de copépodes em amostras de água natural tratadas com azadiractina sugere a possibilidade de uma alteração ecológica significativa na comunidade do zooplâncton alterando assim o equilíbrio do sistema podendo gerar efeitos em diferentes níveis tróficos do ambiente aquático (KREUTZWEISER et al., 2004).

Também já foi relatado que alevinos e juvenis de pacu (Piaractus mesopotamicus) quando expostos a azadiractina de forma aguda apresentaram alteração comportamental significativa e 100\% de mortalidade (CRUZ; MACHADO-NETO; MENEZES, 2004). Em outros experimentos de exposição aguda a azadiractina envolvendo peixes, no caso, carpas (Cyprinus carpio) também foram relatados efeitos da toxicidade do composto. No primeiro, foram descritas perda na mobilidade e alterações motoras, junto com alterações hematológicas, tais como diminuição no hematócrito e em outros índices hematimétricos (MURUSSI et al., 2016b). Já, no segundo trabalho, a análise histológica das brânquias de carpas apresentou alterações do tipo hipertrofia, hiperplasia e aumento na produção de muco com o aumento a exposição à azadiractina sugerindo que os exemplares expostos estavam respondendo com mecanismos de defesa a exposição do composto (MURUSSI et al., 2016a). 
Alguns poucos estudos de genotoxicidade com azadiractina já foram realizados. Em um trabalho que foi testado a exposição de azadiractina e cloreto de cádmio separadamente e conjuntamente em peixes da espécie Oreochromis mossambicus os autores relatam aumento das alterações cromossômicas em diferentes tipos celulares para ambos os fatores (CHANDRA; KHUDA-BUKHSH, 2004). Entretanto, na análise conjunta dos fatores, os autores sugerem que possa existir uma ação antagonista da azadiractina, antagonizando agentes mutagênicos como o cloreto de cádmio. Porém, alertam que tentar usar a azadiractina como agente antimutagênico é limitado devendo ser restrito a águas confinadas e fortemente poluídas. Além disso, sugerem o uso com cautela da azadiractina devido ao seu potencial genotóxico em organismos não alvos no meio aquático (CHANDRA; KHUDA-BUKHSH, 2004).

Foi demonstrado efeito de citotoxidade e genotoxidade da azadiractina em relação à exposição de células de raiz de cebola (Allium cepa) medidos como índice mitótico e índice de aberrações mitóticas. Entretanto, quando os testes de exposição foram feitos com a azadiractina sofrendo ação da exposição da luz solar, os autores observaram uma redução significativa nos índices medidos. Assim sugeriram que a exposição à luz solar pode promover a fotodegradação da azadiractina reduzindo os seus efeitos. Por isso, também sugeriram que o seu efeito no ambiente não seria persistente (KWANKUA et al., 2010).

Os pesticidas, independentemente de sua origem ser natural ou sintética, podem persistir ou deixar resíduos nas águas, podendo entrar em contato com diversos sistemas hídricos, afetando a vida aquática, especialmente os peixes. Além disso, peixes (assim como outros seres de vida aquática) servem de alimento para populações humanas, podendo servir de via indireta a tais contaminantes (COPATTI; GARCIA; BALDISSEROTTO, 2009).

Assim, para este trabalho pretendemos avaliar o efeito genotóxico da azadiractina em concentrações inferiores a que é atualmente utilizada na agricultura orgânica sobre o ambiente aquático utilizando como organismo teste peixes da espécie D. rerio. Uma vantagem da utilização de $D$. rerio como organismo teste está no seu tamanho, relativamente pequeno quando comparado a de outras espécies, de modo que eles podem ser facilmente controlados em grande número no laboratório (KISHI et al., 2003). Além disso, os estudos toxicológicos e clínicos podem ser realizados num formato miniaturizado, o que minimiza as quantidades de produtos químicos para implantar e reduz os volumes de resíduos potencialmente perigosos (HILL et al., 2005; SPITSBERGEN; KENT, 2003). 


\section{MATERIAIS E MÉTODOS}

\subsection{Delineamento experimental}

O experimento consistiu em um teste de exposição com o organismo teste $D$. rerio ao azadiractina em três concentrações diferentes inferiores a concentração recomendada de uso deste biopesticida que é de 1,2g/100 L, equivalente $12 \mu \mathrm{g} / \mathrm{mL}$ de princípio ativo (ANVISA, 2016). Assim, foram expostos três grupos testes (1,2; 0,3 e 0,15 $\mu \mathrm{g} / \mathrm{mL})$, um controle negativo $(\mathrm{CN})$ e um controle positivo (CP) CuSO4 $(0,1 \mathrm{mg} / \mathrm{L})$. O presente trabalho faz parte do projeto "Genotoxicidade Ambiental do Vale do Rio Pardo, RS" aprovado no comitê de ética em pesquisa de animais da UNISC sob o $n^{\circ}$ 016/14. Os resultados referentes à exposição à azadiractina foram avaliados quanto ao efeito da genotoxicidade através do EC em um período de até sete dias. Após sete dias, os exemplares vivos de cada grupo e que não foram utilizados no EC, os grupos foram transferidos para novos aquários livres de contaminação pelo biopesticida para avaliar o tempo de sobrevivência em até duas semanas (Figura 2).

\section{Figura 2. Delineamento experimental}

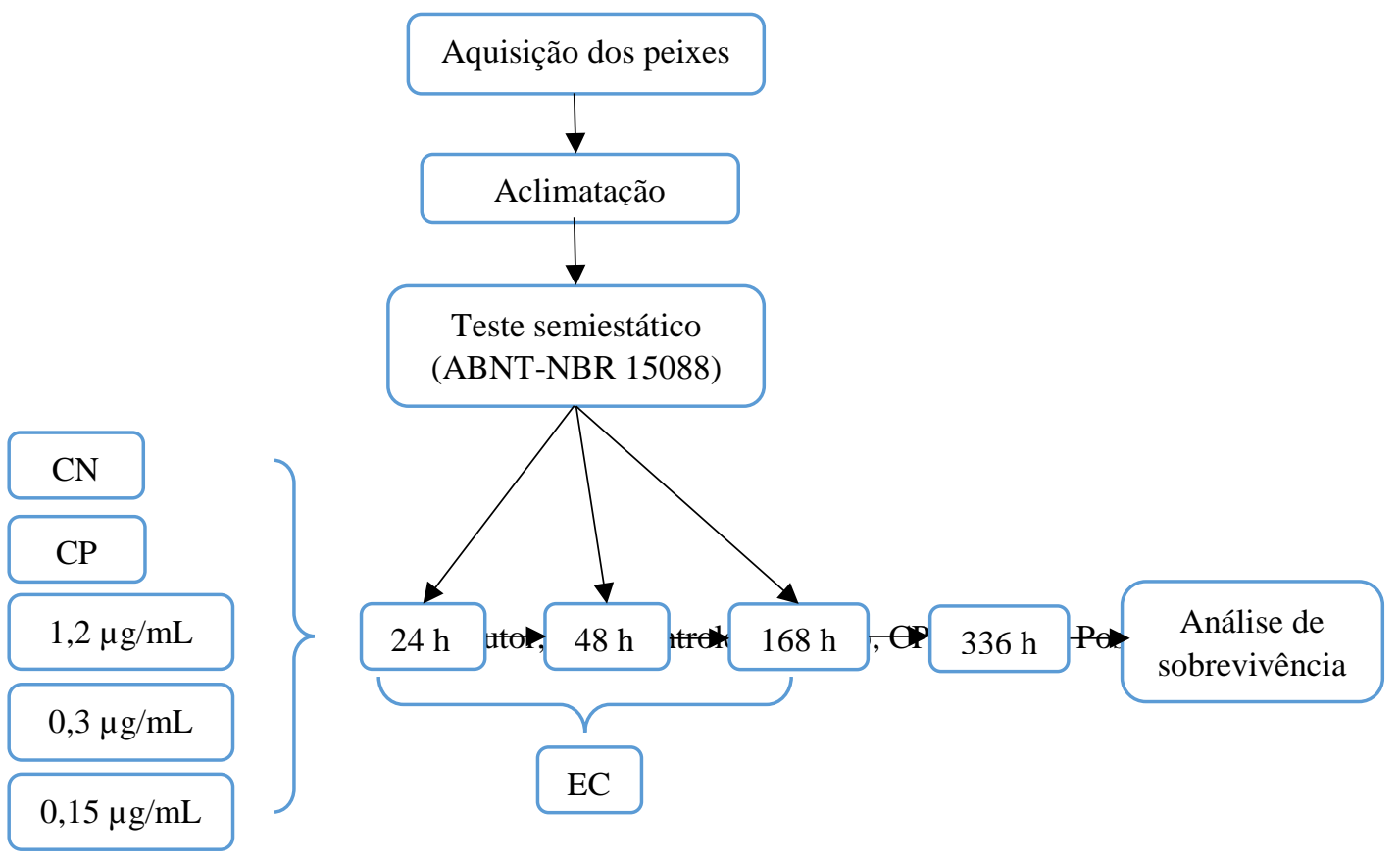

\subsection{Amostras}


Foram adquiridos comercialmente cerca de 150 exemplares de D. rerio tendo todos da mesma linhagem e idade. Os exemplares foram aclimatados em um aquário com 75 litros de água (2 peixes/L) por três semanas nas seguintes condições: água reconstituída ( $\mathrm{pH} 7,4$;

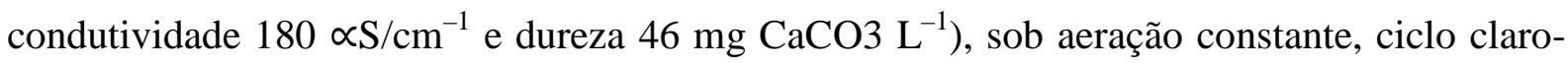
escuro de 12 horas luz, alimentação duas vezes ao dia com ração comercial específica (ad libitum) e renovação de 1/3 da água total do aquário a cada 48 horas. Todos os parâmetros (oxigênio dissolvido, turbidez, condutividade elétrica, $\mathrm{pH}$ e temperatura), foram monitorados diariamente e mantidos nas condições determinadas pela norma 15088 da Associação Brasileira de Normas Técnicas (ABNT NBR 15088) que foi utilizada como base para o teste (ABNT, 2004).

\subsection{Teste de exposição à Azadiractina}

Foi utilizado como modelo o teste semiestático NBR 15088, o qual já é consolidado na ecotoxicologia aquática (ABNT, 2004). Este teste consiste em realizar a renovação de 1/3 da solução de tratamento de cada aquário a cada 48 horas de exposição dos indivíduos durante o período do teste.

Os exemplares aclimatados foram separados em cinco grupos de 20 indivíduos cada. O experimento teve um grupo controle negativo $(\mathrm{CN})$ com água reconstituída ( $\mathrm{pH}$ 7,4;

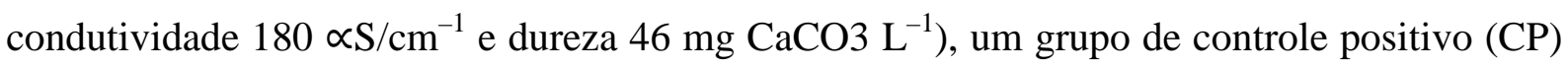
com água reconstituída mais CuSO4 $(0,1 \mathrm{mg} / \mathrm{L})$ e três grupos testes com água reconstituída acrescida de azadiractina, nas seguintes concentrações: $1,2 \mu \mathrm{g} / \mathrm{mL} ; 0,3 \mu \mathrm{g} / \mathrm{mL}$ e $0,15 \mu \mathrm{g} / \mathrm{mL}$. Para cada grupo foram utilizados dois aquários de $5 \mathrm{~L}$ (2 peixes/L). A adição da amostra de azadiractina foi através de pipetagem na água reconstituída. Em seguida, ela foi submetida à aeração e agitação contínua durante duas horas antes de ser utilizada. Imediatamente após, ocorreu à transferência dos exemplares de $D$. rerio dando início ao teste de exposição.

\subsection{Ensaio cometa}

A coleta de sangue dos peixes foi realizada em corte único separando a cabeça do restante do corpo, após a dessensibilização do animal em banho de gelo $4^{\circ} \mathrm{C}$. A amostra de sangue foi obtida com o auxílio de micropipeta e transferida diretamente para um microtubo contendo 1mL de meio de cultura desenvolvido pelo Roswell Park Memorial Institute (RPMI- 
1640) na proporção de 1:100. O protocolo de EC foi realizado como descrito a seguir com ligeiras modificações (SINGH, 2016). De cada amostra preparada, $50 \mu \mathrm{L}$ foram misturados em $50 \mu \mathrm{L}$ de agarose de baixo ponto de fusão e então espalhadas sobre uma lâmina de microscopia pré-cobertas com agarose normal (1,5\%). Sobre a amostra espalhada na lâmina foi colocada lamínula. $\mathrm{O}$ conjunto foi armazenado a $4^{\circ} \mathrm{C}$ por 10 minutos para solidificação da agarose. Em seguida, as lamínulas foram removidas e as lâminas acondicionadas em cubeta de vidro contendo solução de lise (2,5 M NaCl, 100 mM, $\mathrm{Na}_{2}$ EDTA, 10 mM TRIS, pH 10, 1\% Triton X-100, 10\% DMSO) por 1 hora. Após, as lâminas foram submersas em tampão alcalino (15 min) para o desenovelamento do DNA, seguido de eletroforese (20 min, 300mA, 25v). Ao término da eletroforese as lâminas foram neutralizadas (0,4 M TRIS, pH 7,5), fixadas e posteriormente coradas com Nitrato de Prata. Todo o procedimento, desde a preparação da amostra ocorreu sem exposição de luz UV de modo a evitar danos ao DNA por essa radiação. Foi utilizada para iluminação somente luz indireta de LED e com filtro para o comprimento de onda do espectro amarelo. Para cada eletroforese, também se utilizou um controle positivo em que a amostra a ser colocada na lâmina era exposta ao peróxido de hidrogênio. É sabido que o peróxido de hidrogênio provoca danos no DNA que podem ser visualizados no EC. Este controle teve por objetivo garantir que o procedimento de eletroforese estava confiável quanto à detecção de danos no DNA. Os resultados esperados devem ser semelhantes ao do grupo CP de exposição e significativamente menores que os do CN. A análise dos nucleoides baseou-se na contagem de células em microscopia óptica (400x) classificadas quanto a magnitude da lesão no nucleoide em cinco classes variando de zero (sem dano) a quatro (dano máximo). Foram analisados 100 nucleoides por lâmina em quintuplicata para obtenção dos parâmetros Frequência de Dano (FD) e Índice de Dano (ID). A FD foi calculada como percentual de nucleoides com dano em relação ao total, enquanto o ID é calculado pela fórmula ID $=\left[\left(n^{\circ}\right.\right.$ de nucleoides de classe 1$\left.) \times 1\right]+\left[\left(n^{\circ}\right.\right.$ de nucleoides de classe 2$) \times 2]+\left[\left(n^{\circ}\right.\right.$ de nucleoides de classe 3$\left.) \times 3\right]+\left[\left(n^{\circ}\right.\right.$ de nucleoides de classe 4$\left.) \times 4\right]$, sendo expresso em unidades arbitrárias variando de 0 a 400 (COLLINS et al., 2008).

\subsection{Análise de sobrevivência}

Dos 20 exemplares de cada grupo do experimento, 15 foram utilizados para o EC em até sete dias. Os exemplares sobreviventes foram então transferidos para novos aquários que continham água livre de contaminantes, igual à utilizada para o grupo CN. Estes exemplares 
foram então mantidos conforme as recomendações da ABNT NBR 15088 e acompanhados quanto a mortalidade por mais um período de sete dias. Os resultados foram usados para se calcular a análise de sobrevivência.

\subsection{Análise estatística}

Os resultados de FD e ID dos grupos testes foram ajustados em relação ao CN dividindo-se o resultado de cada amostra pela média do CN. Desta forma, pode-se comparar o grupo teste tanto em relação ao $\mathrm{CN}$ a cada momento de exposição, como também a variação da genotoxicidade ao longo do tempo de exposição em cada grupo. Para avaliar a genotoxicidade em cada momento (24, 48 e 168 h) utilizou-se o teste U de Mann-Whitney comparando-se cada grupo teste contra o CN daquele momento. Para a análise da variação da genotoxicidade de cada grupo teste ao longo do tempo utilizou-se a Análise de Variância (ANOVA) de Duas Vias seguida do teste pós-teste de Tukey para múltiplas comparações. Todas as análises foram realizadas com o programa estatístico GraphPadPrism6.01 considerando-se o nível de significância de $\alpha=0,05$.

\section{RESULTADOS}

\subsection{Genotoxicidade}

A avaliação da genotoxicidade foi realizada através do EC. Testes de exposição foram realizados com uma concentração de azadiractina de $1,2 \mu \mathrm{g} / \mathrm{mL}, 0,3 \mu \mathrm{g} / \mathrm{mL}$ 0,15 $\mu \mathrm{g} / \mathrm{mL}$. Essas concentrações representam valores muito inferiores ao permitido pela legislação que é de 1,2g/100 L (12 $\mu \mathrm{g} / \mathrm{mL})$ para a azadiractina para exercer sua função de biopesticida (ANVISA, 2016). Dessa forma, a ideia foi mimetizar o possível efeito da azadiractina quando em contato com os meios aquáticos onde sofrerá diluição. Os resultados obtidos do EC sugerem que a azadiractina tem como efeito um aumento significativo da genotoxidade avaliada em eritrócitos de $D$. rerio. Esse efeito pode ser observado em todas as concentrações testadas no que diz respeito aos parâmetros FD e ID. Essa genotoxicidade significativamente aumentada em relação ao CN foi observada tanto em $24 \mathrm{~h}$, como em $48 \mathrm{~h}$ como ao final do ensaio em todas as concentrações testadas de azadiractina (Tabela 1). 
Tabela 1. Frequência e Índice de Dano em eritrócitos de $D$. rerio expostos a azadiractina segundo as normas do teste semiestático ABNT NBR 15088

\begin{tabular}{|c|c|c|c|c|c|c|c|c|c|}
\hline & \multirow[b]{2}{*}{ Grupos } & \multicolumn{4}{|c|}{ FD } & \multicolumn{4}{|c|}{ ID } \\
\hline & & Média & (DP) & Mediana & (mín-máx) & Média & (DP) & Mediana & (mín-máx) \\
\hline \multirow[t]{4}{*}{$24 \mathrm{~h}$} & $\mathbf{C N}$ & 1 & 0,05 & 0,97 & $(0,94-1,08)$ & 1 & 0,14 & 0,91 & $(0,88-1,24)$ \\
\hline & $1,2(\mu \mathrm{g} / \mathrm{mL})$ & 1,59 & 0,04 & $1,59 * *$ & $(1,52-1,64)$ & 1,9 & 0,1 & $1,87 * *$ & $(1,79-2,02)$ \\
\hline & $0,3(\mu \mathrm{g} / \mathrm{mL})$ & 1,65 & 0,03 & $1,66^{* *}$ & $(1,60-1,69)$ & 2,31 & 0,1 & $2,27 * *$ & $(2,23-2,27)$ \\
\hline & $0,15(\mu \mathrm{g} / \mathrm{mL})$ & 1,71 & 0,01 & $1,71^{* *}$ & $(1,71-1,72)$ & 2,7 & 0,06 & $2,69 * *$ & $(2,60-2,77)$ \\
\hline \multirow[t]{4}{*}{$48 \mathrm{~h}$} & CN & 1 & 0,05 & 0,97 & $(0,94-1,08)$ & 1 & 0,14 & 0,91 & $(0,88-1,24)$ \\
\hline & $1,2(\mu \mathrm{g} / \mathrm{mL})$ & 1,3 & 0,07 & $1,33^{* *}$ & $(1,19-1,34)$ & 1,39 & 0,12 & $1,39 * *$ & $(1,22-1,53)$ \\
\hline & $0,3(\mu \mathrm{g} / \mathrm{mL})$ & 1,48 & 0,03 & $1,47 * *$ & $(1,44-1,52)$ & 1,71 & 0,1 & $1,68^{* *}$ & $(1,64-1,86)$ \\
\hline & $0,15(\mu \mathrm{g} / \mathrm{mL})$ & 1,58 & 0,03 & $1,58 * *$ & $(1,54-1,62)$ & 2,12 & 0,02 & $2,12 * *$ & $(2,09-2,15)$ \\
\hline \multirow[t]{4}{*}{$168 \mathrm{~h}$} & $\mathbf{C N}$ & 1 & 0,08 & 0,98 & $(0,90-1,11)$ & 1 & 0,11 & 0,98 & $(0,89-1,16)$ \\
\hline & $1,2(\mu \mathrm{g} / \mathrm{mL})$ & 1,12 & 0,03 & $1,12 *$ & $(1,10-1,16)$ & 1,17 & 0,06 & $1,19 *$ & $(1,08-1,22)$ \\
\hline & $0,3(\mu \mathrm{g} / \mathrm{mL})$ & 1,34 & 0,05 & $1,35^{* *}$ & $(1,29-1,42)$ & 1,62 & 0,19 & $1,49 * *$ & $(1,48-1,91)$ \\
\hline & $0,15(\mu \mathrm{g} / \mathrm{mL})$ & 1,32 & 0,04 & $1,31^{* *}$ & $(1,29-1,39)$ & 1,63 & 0,13 & $1,61^{* *}$ & $(1,52-1,85)$ \\
\hline
\end{tabular}

FD: Frequência de Dano; ID: Índice de Dano; CN: Controle Negativo; DP: Desvio Padrão; Teste de MannWhitney grupos teste comparados contra o $\mathrm{CN} ;{ }^{*} \mathrm{p}<0,05 ;{ }^{*} \mathrm{p}<0,01$

A utilização dos resultados de FD e ID ajustados em relação à média do CN permitiu a possibilidade de comparar-se os efeitos genotóxicos ao longo do tempo através de uma ANOVA de duas vias. Os resultados sugerem que a genotoxicidade avaliada pela FD e ID do EC apresentaram uma queda significativa no período de $24 \mathrm{~h}$ em relação ao de $48 \mathrm{~h}$ nos 3 grupos testes $(\mathrm{p}<0,001)$. Essa diminuição significativa da genotoxicidade continua sendo observada em todas as concentrações, com exceção do grupo de concentração de $0,3 \mu \mathrm{g} / \mathrm{mL}$, quando comparamos FD e ID entre de 48h até 168h (Figura 3). É interessante observar que embora a genotoxicidade de 24 para 48h apresente uma redução maior do que redução entre 48 e 168h, todos os grupos testes sempre apresentaram a FD e ID significativamente aumentada em relação ao grupo CN em todos os momentos do teste (Tabela 1). 
Figura 3. Frequência de Dano (FD) e Índice de Dano (ID) ao longo do tempo.
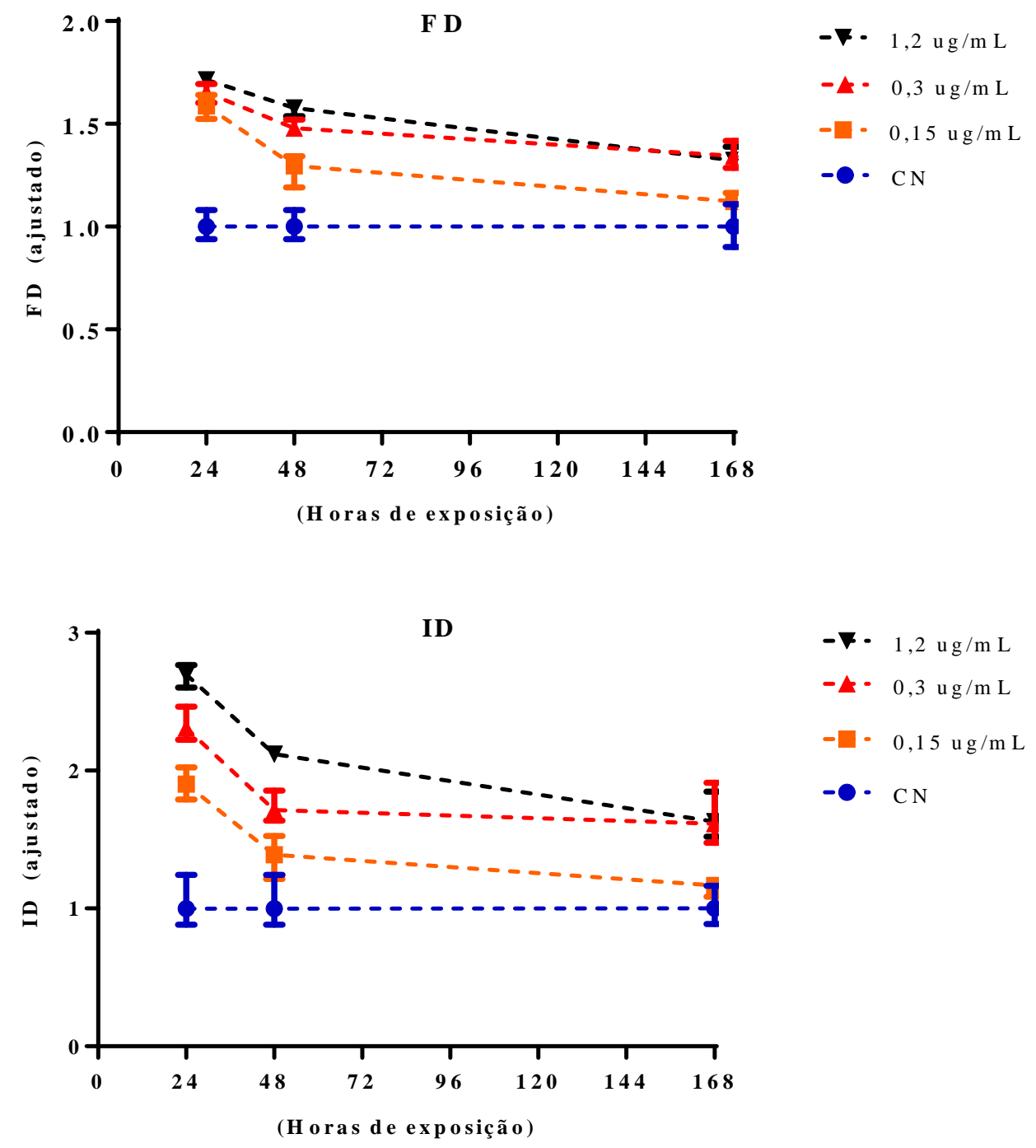

\subsection{Análise de Sobrevivência}

Os exemplares não utilizados ao longo do EC foram transferidos para aquários com água reconstituída como a do CN. Eles foram acompanhados até a ocorrência de sua morte, o que aconteceu para todos os indivíduos, independente da concentração de azadiractina, até o 
$13^{\circ}$ dia. Este resultado de $100 \%$ de mortalidade em 13 dias após o início do teste somente para os grupos expostos a azadiractina evidencia a significativa toxicidade do composto em relação ao CN. Cabe salientar que os exemplares do grupo exposto como CP para o EC com água contendo CuSO4 (0,1 mg/L) também foram acompanhados no mesmo período e não apresentaram mortalidade (dados não mostrados). Contudo, quando comparamos as curvas de sobrevivência não encontramos diferença significativas relacionadas à dose da azadiractina, sugerindo que mesmo a concentração mais baixa de azadiractina apresentou um efeito significativo de toxicidade, embora no grupo de maior concentração um indivíduo já tenha morrido nas primeiras 12 horas de exposição (Figura 4).

Figura 4. Análise de sobrevivência dos exemplares de $D$. rerio em um período de 13 dias após a exposição a azadiractina.

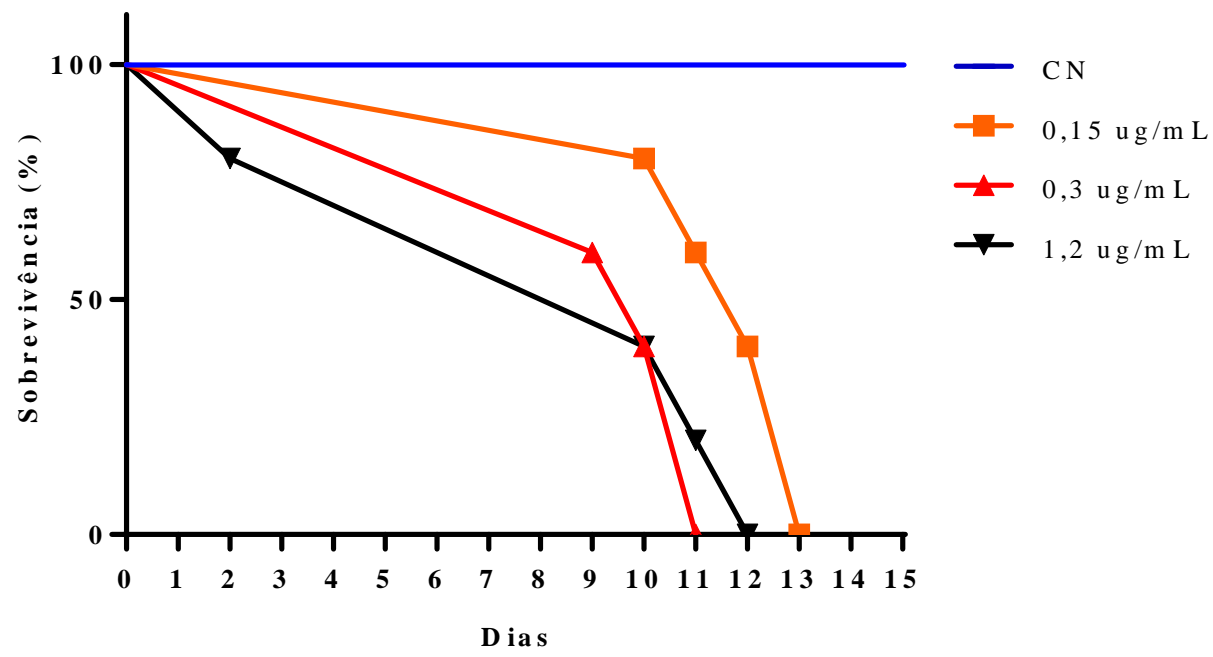

\section{DISCUSSÃO}

A grande maioria dos estudos envolvendo a azadiractina estão relacionados aos efeitos da sua toxicidade como potencial de biopesticida (BENELLI et al., 2017), porém existem autores que revisaram e alertaram sobre o efeito tóxico deste composto (RAJ, 2014), entretanto os estudos com ferramentas que avaliam a genotoxicidade são muito mais raros.

Apesar da azadiractina ser um biopesticida referido como eco-amigável devido a sua origem natural, o seu uso deve ser visto com cautela, pois muitos dos seus efeitos ainda não são compreendidos (CHANDRA; KHUDA-BUKHSH, 2004). Em nosso trabalho, o aumento da FD e ID nos eritrócitos de D. rerio, já em 24 horas, aliado a manutenção desse efeito de genotoxicidade, até o final do experimento, sugerem que o composto ativo, azadiractina, 
persista na água tendo efeitos genotóxicos diretos ou através de seus catabólitos nos sistemas biológicos do peixe modelo do experimento.

Mesmo que a azadiractina possa ser degradada a partir da exposição solar (KWANKUA et al., 2010), os seus efeitos genotóxicos são persistentes quando absorvida pelo organismo. Em ambientes aquáticos naturais ou artificiais a radiação solar pode ser filtrada no espelho da água diminuindo a capacidade de fotodegradação sobre vários compostos orgânicos, tais como azadiractina e assim promovendo a sua persistência no ambiente.

A persistência na água já foi sugerida por outros autores (HOLMES; MACQUARRIE, 2016; KREUTZWEISER et al., 2004) que alertaram que esse efeito pode se propagar em diferentes níveis tróficos e por isso deve-se ter cuidado com o uso da azadiractina, bem como de outros compostos pesticidas naturais ou sintéticos.

Estudos de genotoxicidade sugerem que a azadiractina possa ter um efeito direto sobre a divisão celular afetando a fase mitótica (CHANDRA; KHUDA-BUKHSH, 2004; KWANKUA et al., 2010), embora em um estudo com células de hamster não tenham sido constatados efeitos de genotoxicidade, mas sim antiproliferativos (MOSESSO et al., 2012). Diferentemente destes trabalhos, a nossa avaliação utiliza outra ferramenta, o EC, que avalia danos no DNA em estado inicial baseados em quebras simples e duplas, mas que podem ser reparados. Quando este reparo não ocorre é que o dano pode ser permanente (COLLINS et al., 2008). Assim a utilização do EC com eritrócitos de peixes pode ser uma alternativa para avaliar alterações em nível de DNA e que não ocasionam a perda de viabilidade e/ou vitalidade do organismo teste.

A utilização de compostos que tem azadiractina em sua formulação, tais como os biopesticida a base de óleo de Neem deve ser cautelosa e criteriosa devido aos seus efeitos genotóxicos (CHANDRA; KHUDA-BUKHSH, 2004) e citotóxicos (KWANKUA et al., 2010; MOSESSO et al., 2012).

Esses efeitos podem persistir nos ecossistemas aquáticos (HOLMES; MACQUARRIE, 2016; KREUTZWEISER et al., 2004) e causarem efeitos inclusive sobre a mortalidade. Em um trabalho envolvendo a exposição de alevinos e juvenis de Pacu, Piaractus mesopotamicus, à azadiractina ocorreu 100\% de mortalidade já nas primeiras 24 horas (CRUZ; MACHADO-NETO; MENEZES, 2004). No presente trabalho obteve-se 100\% de mortalidade dos exemplares de $D$. rerio em até 13 dias após a exposição à azadiractina. Como a letalidade não foi imediata e sim em poucos, sugere-se que o efeito genotóxico 
acompanhado até uma semana nos exemplares de D. rerio provavelmente desencadeou alterações na capacidade de manter a homeostase destes organismos levando-os a morte. Essa alta taxa de letalidade decorrente da exposição à azadiractina evidencia o seu potencial de toxicidade em peixes.

\section{CONCLUSÃo}

A azadiractina apresenta potencial de genotoxicidade no ambiente aquático para $D$. rerio, mesmo quando usada em concentrações inferiores à preconizada pela legislação. Além disso, pode-se sugerir que o efeito de genotoxicidade acabe sendo o responsável pelo efeito de letalidade dos organismos testados no presente trabalho. Desta forma, a utilização de biopesticidas, mesmo aqueles classificados para utilização na agricultura orgânica, como é o caso dos que possuem a azadiractina como princípio ativo, requerem mais pesquisas para que as autoridades de saúde possam atestar a sua segurança, de modo a proteger e informar possíveis riscos, tanto para os usuários quanto como para os consumidores, além de prevenir efeitos deletérios sobre os ecossistemas.

\section{AGRADECIMENTOS}

Agradecemos à Universidade de Santa Cruz do Sul - UNISC, à Fundação de Amparo à Pesquisa do Rio Grande do Sul pela concessão da Bolsa PIBIC-FAPERGS, ao Laboratório de Genética e Biotecnologia da Universidade de Santa Cruz do Sul - UNISC e a Secretária do Desenvolvimento Econômico, Ciência e Tecnologia do Rio Grande do Sul (SDECT-RS) financiadora do projeto "Centro de Pesquisa e Treinamento em Biotecnologia (CPTBIO)” pelo apoio e oportunidade de realização da pesquisa.

\section{REFERÊNCIAS}

ABNT, N. B. R. 15088 (2004) Associaçao Brasileira de Normas Técnicas (ABNT). In: Ecotoxicologia aquática-Toxicidade aguda—método de ensaio com peixes. [s.l: s.n.]. v. 15p. 19.

ANVISA. Índice Monográfico - A54 Azadiractina. Disponível em: 
$<$ http://portal.anvisa.gov.br/documents/111215/117782/A54\%2B-

\%2BAzadiractina.pdf/bffd3e47-d3a2-435b-ba58-b8896554b490>. Acesso em: 10 ago. 2016.

BENELLI, G. et al. Neem (Azadirachta indica): towards the ideal insecticide? Natural Product Research, v. 31, n. 4, p. 369-386, 2017. DOI 10.1080/14786419.2016.1214834

BOTTON, M. et al. Eficiência de inseticidas no controle de Eurhizococcus brasiliensis ( Hemiptera : Margarodidae ) na cultura da videira. BioAssay, v. 8, n. 5, p. 2-6, 6 set. 2013. Disponíel em https://www.bioassay.org.br/bioassay/article/view/120. Acesso em: 6 set. 2016. DOI 10.14295/BA.v8.0.120

CAMPOS, E. V. R. et al. Neem Oil and Crop Protection: From Now to the Future. Frontiers in Plant Science, v. 7, n. October, p. 1-8, 2016. Disponível em: http://journal.frontiersin.org/article/10.3389/fpls.2016.01494/full Acesso em: 12 mar. 2017. DOI: 10.3389/fpls.2016.01494

CHANDRA, P.; KHUDA-BUKHSH, A. R. Genotoxic effects of cadmium chloride and azadirachtin treated singly and in combination in fish. Ecotoxicology and Environmental Safety, v. 58, n. 2, p. 194-201, 2004. DOI: 10.1016/j.ecoenv.2004.01.010

CHANDRAMOHAN, B. et al. Characterization and mosquitocidal potential of neem cakesynthesized silver nanoparticles: genotoxicity and impact on predation efficiency of mosquito natural enemies. Parasitology Research, v. 115, n. 3, p. 1015-1025, 16 mar. 2016. Disponível em: http://link.springer.com/10.1007/s00436-015-4829-9 Acesso em: 4 mar. 2017. DOI: $10.1007 / \mathrm{s} 00436-015-4829-9$

COLLINS, A. R. et al. The comet assay: Topical issues. Mutagenesis, v. 23, n. 3, p. 143-151, $2008 . \quad$ Disponível em: https:/oup.silverchaircdn.com/oup/backfile/Content_public/Journal/mutage/23/3/10.1093/mutage/gem051/2/gem05 1.pdf?Expires $=1509149395 \&$ Signature $=$ QoN Acesso em: 26 set. 2016. DOI: 10.1093/mutage/gem051

COPATTI, C. E.; GARCIA, L. D. O.; BALDISSEROTTO, B. Uma importante revisão sobre o impacto de agroquímicos da cultura de arroz em peixes. Biota Neotropica, v. 9, n. 4, p. 235-242, $\quad$ dez. 2009.2 Disponível em: http://www.biotaneotropica.org.br/v9n4/pt/abstract?thematic-

review+bn00509042009\%5Cnhttp://www.biotaneotropica.org.br\%5Cn Acesso em: 04 abr. 2017. DOI:

CRUZ, C.; MACHADO-NETO, J. G.; MENEZES, M. L. D. E. TOXICIDADE AGUDA DO INSETICIDA PARATION METÍLICO E DO BIOPESTICIDA AZADIRACTINA DE FOLHAS DE NEEM (Azadirachta. Pesticidas: Revista de Ecotoxicologia e Meio Ambiente, v. 14, p. 93-102, 2004. Disponível em: Acesso em: DOI: 10.1590/S167606032009000400023

FIRAKE, D. M.; THUBRU, D. P.; BEHERE, G. T. Eco-toxicological risk and impact of pesticides on important parasitoids of cabbage butterflies in cruciferous ecosystem. Chemosphere, v. 168, p. 372-383, 2017. Disponível em: http://linkinghub.elsevier.com/retrieve/pii/S0045653516314552 Acesso em: 04 abr. 2017. DOI: 10.1016/j.chemosphere.2016.10.071 
HILL, A. J. et al. Zebrafish as a Model Vertebrate for Investigating Chemical Toxicity. Toxicological Sciences, v. 86, n. 1, p. 6-19, 1 jul. 2005. Disponível em: http://academic.oup.com/toxsci/article/86/1/6/1654090/Zebrafish-as-a-Model-Vertebrate-forInvestigating Acesso em: 10 mai. 2016. DOI: 10.1093/toxsci/kfi110

HOLMES, S. B.; MACQUARRIE, C. J. K. Chemical control in forest pest management. The Canadian Entomologist, v. 26, p. 1-26, 2016. Disponível em: http://www.journals.cambridge.org/abstract_S0008347X15000711 Acesso em: 04 abr. 2017. DOI: $10.4039 /$ tce.2015.71

KISHI, S. et al. The zebrafish as a vertebrate model of functional aging and very gradual senescence. Experimental Gerontology, v. 38, n. 7, p. 777-786, 2003. Disponível em: https://ac.els-cdn.com/S0531556503001086/1-s2.0-S0531556503001086-

main.pdf?_tid=ed7c25f6-b913-11e7-bf62-

00000aacb360\&acdnat=1508888270_46dffc11c30e25dbacb Acesso em: 10 mai. 2016. DOI: 10.1016/S0531-5565(03)00108-6

KREUTZWEISER, D. P. et al. Some ecological implications of a neem (azadirachtin) insecticide disturbance to zooplankton communities in forest pond enclosures. Aquatic Toxicology, v. 67, n. 3, p. 239-254, 2004. DOI: 10.1016/j.aquatox.2004.01.011

KWANKUA, W. et al. Sunlight decreased genotoxicity of azadirachtin on root tip cells of Allium cepa and Eucrosia bicolor. Ecotoxicology and Environmental Safety, v. 73, n. 5, p. 949-954, jul. 2010. DOI: 10.1016/j.ecoenv.2010.04.001

MORDUE(LUNTZ), A. J.; NISBET, A. J. Azadirachtin from the neem tree Azadirachta indica: its action against insects. Anais da Sociedade Entomológica do Brasil, v. 29, n. 4, p. 615-632, 2000.2 Disponível em: http://www.scielo.br/scielo.php?script=sci_arttext\&pid=S0301-

80592000000400001\&lng=en\&tlng=em Acesso em: 06 mai. 2016. DOI: 10.1590/S030180592000000400001

MOSESSO, P. et al. Cytogenetic analyses of Azadirachtin reveal absence of genotoxicity but marked antiproliferative effects in human lymphocytes and CHO cells in vitro. Toxicology Letters, v. 213, n. 3, p. 361-366, set. 2012. Disponível em: http://linkinghub.elsevier.com/retrieve/pii/S0378427412012337 Acesso em: 09 mar. 2017. DOI: 10.1016/j.toxlet.2012.07.021

MURUSSI, C. R. et al. Acute exposure to the biopesticide azadirachtin affects parameters in the gills of common carp (Cyprinus carpio). Comparative Biochemistry and Physiology Part - C: Toxicology and Pharmacology, v. 180, p. 49-55, 2016a. DOI: 10.1016/j.cbpc.2015.12.003

MURUSSI, C. R. et al. Azadirachtin, a neem-derived biopesticide, impairs behavioral and hematological parameters in carp (Cyprinus carpio). Environmental toxicology, v. 31, n. 11, p. 1381-1388, nov. 2016b. DOI: 10.1002/tox.22143

PAVLOVA, A. K. et al. Laboratory Bioassays with Three Different Substrates to Test the Efficacy of Insecticides against Various Stages of Drosophila suzukii (Diptera: Drosophilidae). Journal of Insect Science, v. 17, n. 1, p. 8, jan. 2017. Disponível em: 
http://jinsectscience.oxfordjournals.org/lookup/doi/10.1093/jisesa/iew100 Acesso em: 09 mar. 2017 DOI: 10.1093/jisesa/iew100

RAJ, A. Toxicological Effect of Azadirachta Indica. Asian Journal of Multidisciplinary Studies, v. 2, n. 9, p. 29-33, 2014. Disponível em: http://www.ajms.co.in/sites/ajms2015/index.php/ajms/article/view/551/486 Acesso em: 06 mai. 2016

REDDY, G. V. P.; ANTWI, F. B. Toxicity of natural insecticides on the larvae of wheat head armyworm, Dargida diffusa (Lepidoptera: Noctuidae). Environmental Toxicology and Pharmacology, v. 42, p. 156-162, mar. 2016. Disponível em: http://linkinghub.elsevier.com/retrieve/pii/S138266891630014X Acesso em: 12 mar. 2017. DOI: 10.1016/j.etap.2016.01.014

SINGH, N. P. The comet assay: Reflections on its development, evolution and applications. Mutation Research - Reviews in Mutation Research, v. 767, p. 23-30, 2016. Disponível em: $\quad$ https://ac.els-cdn.com/0014482788902650/1-s2.0-0014482788902650main.pdf?_tid=789f4350-ba92-11e7-af17-00000aab0f01\&acdnat=15090525 Acesso em: 26 jul. 2016. DOI: 10.1016/0014-4827(88)90265-0

SPITSBERGEN, J. M.; KENT, M. L. The State of the Art of the Zebrafish Model for Toxicology and Toxicologic Pathology Research-Advantages and Current Limitations. Toxicologic Pathology, v. 31, n. 1_suppl, p. 62-87, 2003. Disponível em: http://journals.sagepub.com/doi/10.1080/01926230390174959 Acesso em: 26 jul. 2016. DOI: 10.1080/01926230390174959

VEITCH, G. E.; BOYER, A.; LEY, S. V. The azadirachtin story. Angewandte Chemie International Edition, v. 47, n. 49, p. 9402-9429, 2008. Disponível em: Acesso em: DOI: 10.1002/anie.200802675 